\title{
The effect of locally delivered Tualang honey on healing of periodontal tissues during non-surgical periodontal therapy
}

\author{
Mior Azrizal Ibrahim¹, Zurairah Berahim²*, Azlina Ahmad², Haslina Taib² \\ ${ }^{1}$ Periodontic Specialist Unit, Klinik Pergigian Kangar, 01000 Kangar, Perlis, Malaysia \\ ${ }^{2}$ School of Dental Sciences, Universiti Sains Malaysia, 16150 Kubang Kerian, Kelantan, Malaysia
}

\begin{abstract}
Honey is a sweet, viscous natural substance made from flower nectar by bees. Honey has been used not only as a nutritional source but also for wound healing and to reduce tissue inflammation. Nevertheless, the use of honey in the treatment of periodontitis is not well established. This study aimed to evaluate the effect of locally delivered Tualang honey on periodontal tissue healing by a randomized controlled split-mouth clinical trial involving 20 chronic periodontitis patients with a periodontal pocket depth of $\geq 5 \mathrm{~mm}$. Each site was randomly treated either by scaling and root debridement alone (Control Group) or scaling and root debridement with locally delivered Tualang honey (Test Group). Assessment of probing pocket depth (PPD) and clinical attachment level (CAL) was recorded at baseline and after 6 weeks interval. Gingival crevicular fluid samples were collected from treated pockets at baseline and along with periodontal reassessment to evaluate the level of Matrix Metalloproteinase 8 (MMP-8) and Osteoprotegerin (OPG). Data were analysed by using Wilcoxon Signed Rank Test and Paired Sample t-Test. PPD and CAL were significantly improved after the 6 weeks review $(P=0.001)$ in both groups. However, there was no significant difference in the changes of the PPD, CAL, MMP-8 and OPG levels after the 6 weeks review and in between the groups. In conclusion, within the limitations of this study, the effect of locally delivered Tualang honey on periodontal tissue healing is not evident. Nevertheless, all pockets achieved good periodontal healing.
\end{abstract}

Keywords: matrix metalloproteinase 8, osteoprotegerin, periodontitis, Tualang honey

\section{Introduction}

Honey is a natural substance and food produced by bees from flower nectar. It has been widely known since ancient times, not only for its nutritional value, but also for its ability to heal many kinds of ailments. For example, in pre-ancient Egyptian times,
Received:

12 January 2021

Revised:

15 February 2021

Accepted:

18 March 2021

Published Online:

31 July 2021

\section{How to cite this article:}

Ibrahim, M. A. ., Berahim, Z., Ahmad, A., \& Taib, H. (2021). The effect of locally delivered Tualang honey on healing of periodontal tissues during nonsurgical periodontal therapy . IIUM Journal of Orofacial and Health Sciences, 2(2), 82-92. Retrieved from https://doi.org/10.31436/ijohs. $\mathrm{v} 2 \mathrm{i} 2.65$

\section{Article DOI:}

https://doi.org/10.31436/ijohs. $\underline{\mathrm{v} 2 \mathrm{i} 2.65}$

\section{*Corresponding author}

Address:

School of Dental Sciences, Universiti Sains Malaysia, 16150 Kubang Kerian, Kelantan, Malaysia

Telephone: +609-7675828

Email address:

zurairah@usm.my 
(2007), honey will never spoil if being stored correctly thus it does not have the expiry date. It can be stored at room temperature without losing its properties. Honey is one of the oldest foods in existence found in the tomb of King Tut which is still edible. It also has a prominent level of fructose thus sweeter than the table sugar.

Previous studies have shown that besides having a good source of nutrition, honey also has superior healing and antimicrobial properties. The antimicrobial activity of honey is one of the most important findings that was first reported in 1892 by Van Ketel. Honey has been reported to have an inhibitory effect on around 60 species of bacteria including aerobes and anaerobes, gram-positive and gram-negative (Olaitan et al., 2007). Besides its antimicrobial properties, honey can clear the infection in several ways, including by boosting the immune system, having anti-inflammatory, and antioxidant activities and via stimulation of cell growth (Tan et al., 2009). All types of honey have high sugar content but the low water content and its acidity prevent microbial growth. Honey can inhibit the growth of a wide range of bacteria, fungi, protozoa, and viruses (Tan et al., 2009). Medical grade manuka honey was reported to have high concentrations of methylglyoxal which were believed to play significant role in its antimicrobial activity (Mavric et al., 2008) includes towards oral bacteria (Safii et al., 2017, Badet and Quero, 2011). Manuka honey was also reported to have many similarities with Malaysian Tualang honey (Kishore et al., 2011, Ahmed \& Othman, 2013). Tualang honey is a wild polyfloral honey produced by wild bees known as Apis dorsata. This honey is collected from the beehive which is normally found on the Tualang tree (Koompassia excels), in the Malaysian rainforest. Tualang honey is used commonly as a medicinal product and as a food supplement in Malaysia. It was found that Tualang honey had high antibacterial properties derived from total and nonperoxide activities (Zainol et al., 2013).

Very few studies have been conducted to demonstrate the beneficial effect of honey in the medical and dental fields. The ability of honey to reduce inflammation and improve wound healing has led to the introduction of honey impregnated pads that can act as nonadhesive tissue dressings (Al-Waili, 2005). This approach leads to the stimulation of the healing process and rapidly clears the infection. In dentistry, a study by Atwa et al. (2014) demonstrated that the topical application of honey can modify the $\mathrm{pH}$, reduce bacterial counts, and inhibit bacterial growth. Based on this finding, topical application/chewing of honey might help prevent gingivitis and caries in patients undergoing complex dental treatment.

Periodontitis is considered one of the most common oral diseases in the world. The pathogenic bacteria that reside in the subgingival area are widely recognized as the primary etiologic factor for the disease (Shifrovitch et al., 2009). It is a lifelong inflammatory disease that is characterized by loss of periodontal ligament and alveolar bone. According to National Health and Nutrition Examination Survey 2012, 46\% of adults in United States of America had periodontitis, with $8.9 \%$ having severe periodontitis (Eke et al., 2015). In Malaysia, the National Oral Health Survey for Adult (NOHSA, 2010) showed that the prevalence of periodontal disease in all levels of severity is increasing from $90.2 \%$ in the year 2000 up to $94 \%$ in 2010 .

The clinical treatment of chronic periodontitis is initiated by non-surgical periodontal therapy (NSPT); patient motivation and oral hygiene instructions, followed by removal of plaque and calculus to achieve a clean root surface by scaling and root surface debridement (SRD). It is widely accepted that effective periodontal therapy for plaque-related disease requires the elimination of inflammation by establishing a biologically acceptable 'clean' root surface (Dentino et al., 2013). However, the success of periodontal therapy may not be achieved by NSPT alone. Hirschfeld and Wasserman (1978) found out that about $20 \%-30 \%$ of all chronic periodontitis cases do not respond favourably to conventional periodontal treatment. Local antimicrobial delivery such as minocycline gel, chlorhexidine chip, and doxycycline gel have been used as an adjunct 
to SRD which were demonstrated to provide additional benefit over SRD alone (Hanes and Purvis, 2003). But the use of antimicrobial agent particularly antibiotics is not appropriate for long term used. As honey was known to provide various beneficial effects in curing diseases, it is anticipated to possess similar action in treating periodontal disease. Therefore, this study was conducted to investigate the effect of locally applied Tualang honey on the healing of periodontal tissues as an adjunct to SRD.

\section{Materials and Methods}

\section{Study design and sampling}

This was a randomized controlled splitmouth clinical trial on chronic periodontitis patients with a follow-up period of 6 weeks. Each patient represents both experimental and control subjects with either right or left side of jaw as the experimental site determined by randomization. Chronic periodontitis patients attending Dental Clinic, Hospital USM, Kelantan was chosen as our source population. Sample size was calculated by using PS software version 3.1.2 by Dupont and Plummer (2009). A total of 20 subjects were included in this study after fulfilled the inclusion and exclusion criteria. The split-mouth design was used in this study, whereby the teeth with a pocket depth of $5 \mathrm{~mm}$ or more in the right and left quadrants in each patient were assigned into either control group or experimental group by using an opaque sealed envelope contained a piece of paper which determined whether a patient receives honey on either left or right quadrant. The envelope was chosen by the patient. Those who were diagnosed with chronic periodontitis (Armitage, 1999) with minimum periodontal pocket depth (PPD) of $5 \mathrm{~mm}$ on at least 3 sites on each quadrant, aged between 20 to 65 years old, and maintained optimum oral hygiene were included. Chronic periodontitis is either localized $(\leq$ $30 \%$ of periodontal sites with PPD greater than $3 \mathrm{~mm}$ ) or generalized $(\geq 30 \%$ of periodontal sites with PPD greater than $3 \mathrm{~mm}$ ) with evidence of alveolar bone loss equal to or greater than $3 \mathrm{~mm}$ in the radiograph. In this study, only sites with minimum of $5 \mathrm{~mm}$ PPD were selected as these sites possess difficulty for patient to clean that required root debridement. Patients taking antibiotics 3 months prior to the study, having uncontrolled systemic disease, smokers, taking medications that affect the gingiva, have known allergy towards honey and taking honey regularly were excluded from this study.

The conduct of this study was fully conformed to the local practices, laws, and regulations. Ethical clearance was obtained from the Human Research and Ethics Committee, Universiti Sains Malaysia, protocol code USM/JEPeM/15090301 on $4^{\text {th }}$ January 2016. Written informed consent was obtained from each subject prior to participation.

\section{Clinical procedures}

Patients were briefed about the study procedures and the informed written consent was taken. Patients' information including patient particulars, intraoral examination, orthopantomogram radiograph, and periodontal charting were recorded in a Data Collection Form. Periodontal parameters such as Plaque Index (PI) (O'Leary, 1972), Gingival Index (GI) (Ainamo, 1975), PPD, and Clinical Attachment Level (CAL) were recorded at baseline and 6 weeks after scaling and root debridement. Calibration of the clinical measurement for periodontal parameters was conducted prior to the data collection. Inter and intra examiner agreements were achieved.

The gingival crevicular fluid (GCF) was collected from PPD $\geq 5 \mathrm{~mm}$ in control and experimental sides for each subject from two buccal sites of two different teeth GCF was collected by using Periopaper (Oraflow Inc) strip before scaling at baseline and after 6 weeks at the same sites during the review visit. The collection method was adapted from Guentsch et al. (2011). Samples were collected in the morning, between 9 am to $12.30 \mathrm{pm}$. Prior to GCF collection, the 
supragingival plaque and calculus were carefully removed by using a hand scaler. Subjects were instructed to rinse their mouth with distilled water to wash out food debris and exfoliated cells. The sites to be sampled were isolated with cotton rolls and gently air-dried to prevent saliva contamination. Periopaper strip was gently inserted for 30 seconds into the periodontal pocket until a minimum of resistance felt. The paper strip that absorbed blood from the pocket was discarded and sampling was repeated after 90 seconds. Paper strips from each group were removed and placed in a test tube containing $500 \mu \mathrm{l}$ bidistilled water which were eluted at $4^{\circ} \mathrm{C}$ overnight. After being centrifuged at $400 \mathrm{~g}$ for 4 minutes, the paper points/strips were removed; the supernatants were kept frozen at $-20^{\circ} \mathrm{C}$ until assayed.

All subjects received a course of NSPT consisting of motivation, oral hygiene instructions (emphasizing proper tooth brushing technique, flossing, interdental brush, and mouthwash usage), scaling, polishing and root debridement with an ultrasonic scaler and Gracey curettes (Schwert, Germany) done by a periodontal registrar (MAMI). The control group received SRD with normal saline irrigation on sites with PPD $\geq 5 \mathrm{~mm}$. The experimental group received SRD with normal saline irrigation and locally delivered $0.5 \mathrm{ml}$ nondiluted Tualang honey on sites with PPD $\geq 5$ $\mathrm{mm}$. The Tualang honey was delivered to the sites until overflows using a syringe with plastic catheter of cannula $20 \mathrm{~g}$ (B Braun) attached to it. Subjects were reviewed at 6 weeks to re-evaluate the clinical periodontal parameters and for the second collection of the GCF sample using the same method. The CONSORT diagram of trial is shown in figure 1.

\section{Biomarker analysis}

For this study, the level of MMP-8 and OPG were determined to compare the healing of periodontal tissue after SRD in patients with chronic periodontitis. The concentrations of the MMP-8 and OPG, in eluted GCF were determined by commercially available
Human Quantikine Enzyme-Linked Immunoabsorbent Assay (ELISA) kits by Elabscience Biotechnology Incorporation as described in the manufacturer's instruction. The ELISA kit is based on the SandwichELISA method. The micro ELISA plate which was provided in the kit has been pre-coated with an antibody specific to human MMP-8 and OPG. To ensure data consistency, the clinical parameters evaluation, GCF samples collection, and laboratory works were done and recorded by one clinical researcher. During biomarker detection with ELISA kit, duplication of each sample was performed. Prior to biomarker detection assay, pre-run test was done on both MMP-8 and OPG to ensure the proteins concentration in eluted GCF is detectable within the standard range. The optical density (OD) and concentration of each well of the micro ELISA plate were determined with a microplate reader with $450 \mathrm{~nm}$ wavelength filter (SkanIt Software 2.4.3 RE for Thermo Scientific ${ }^{\mathrm{TM}}$ Varioskan $^{\mathrm{TM}}$ Flash Multimode Reader).

\section{Statistical analysis}

Data were processed and analysed using the IBM Statistical Package for Social Sciences (SPSS) Statistics Version 24 (IBM Corporation, USA). The means and standard deviations were computed for all patient's data, clinical parameters, and protein biomarkers concentration. Analysis was carried out using non-parametric tworelated samples test; Wilcoxon Signed Rank Test, to compare PI, GI, and for comparison of protein biomarkers concentration between control and experimental groups from baseline and at 6 weeks. The results were expressed in median and interquartile range (IQR). Independent t-test was used to compare the mean changes of PPD and CAL between both groups and was expressed in means and standard deviations (SD). The level of significance was set at $\mathrm{P}<0.05$ and 95\% CI (Confidence Interval).

\section{Results}

Demographical data 
Twenty subjects with a mean (SD) age of 46.5 (11.9) were participated and completed the trial. There were $12(60 \%)$ males and 8 $(40 \%)$ females with the total number of pockets treated were 194 and 176 sites in the control and experimental group respectively. In terms of medical background, five subjects had medical illnesses such as heart disease, hypertension, hypercholesterolemia, bronchial asthma, and heart septal defect, which were under control (Table 1). Periodontal tissue healing occurred in all subjects with no adverse effects such as pain, burning sensation, or any other uncomfortable feeling. There was also no allergic reaction towards honey reported from any of the subjects.

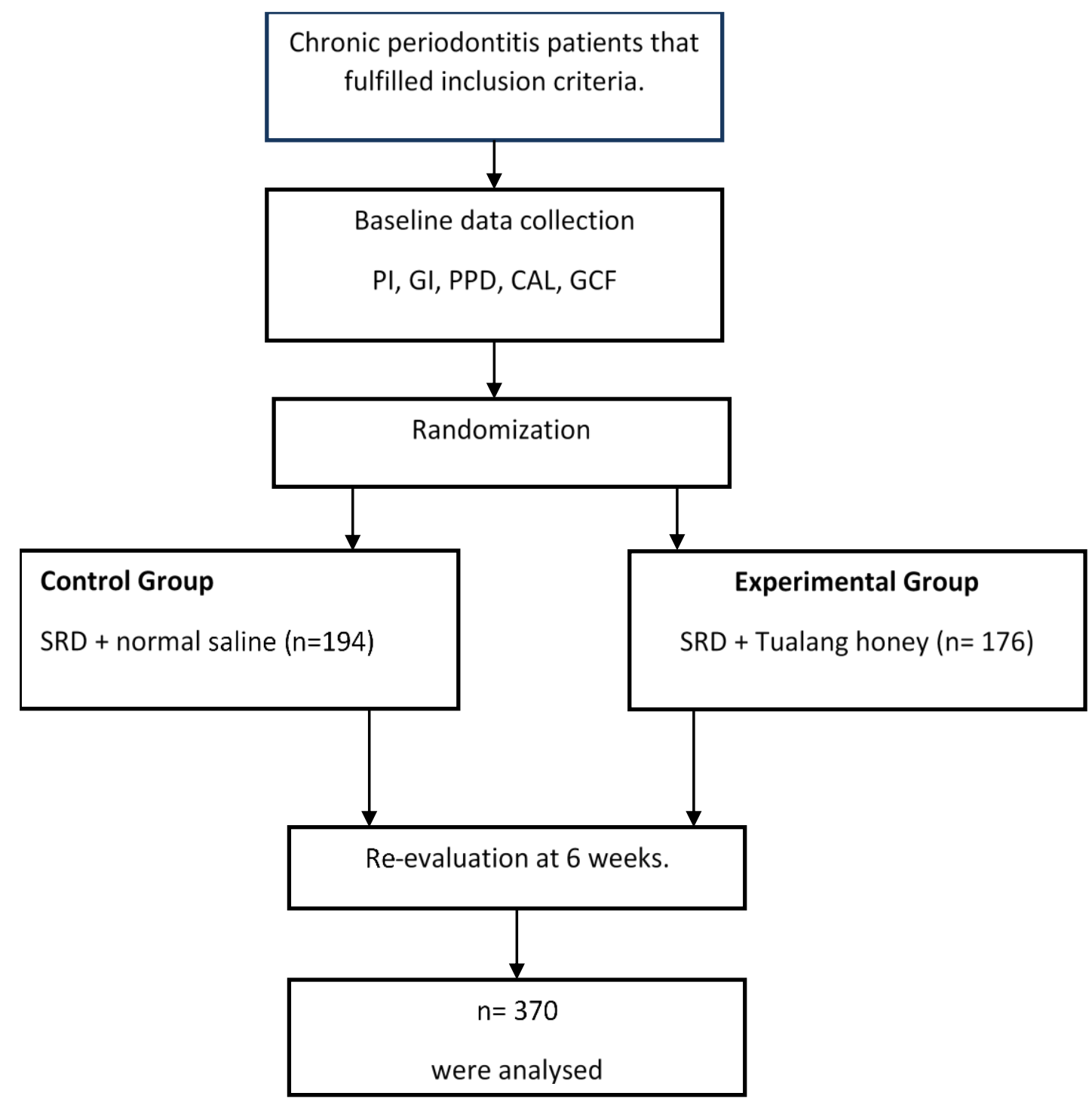

Figure 1. Flow chart of the study trial. (Plaque index $=$ PI, Gingival index $=$ GI, Periodontal pocket depth = PPD, Gingival crevicular fluid $=$ GCF $)$ 
Table 1. Characteristic of the study subjects $(n=20)$

\begin{tabular}{lll}
\hline Variables & Mean (SD) & Frequency (\%) \\
\hline $\begin{array}{l}\text { Age } \\
\text { Gender }\end{array} \quad$ Male & $46.50(11.96)$ & - \\
$\quad-$ & $12(60.0)$ \\
$\quad$ Female & - & $8(40.0)$ \\
$\begin{array}{l}\text { Systemic disease } \\
\quad \text { Yes }\end{array}$ & - & $5(25.0)$ \\
$\quad$ No & - & $15(75.0)$ \\
PPD sampled sites (mm) & & \\
$\quad$ Control & & - \\
$\quad$ Experimental & $5.51(0.53)$ & - \\
\hline
\end{tabular}

The effect of local delivery of Tualang honey as an adjunct during SRD versus SRD alone on periodontal parameter

PI and GI were maintained at a satisfactory level from baseline and after 6 weeks in which only slight reduction with no significant changes were observed for PI $(\mathrm{P}=0.668)$ and $\mathrm{GI}(\mathrm{P}=0.052)$ (Table 2$)$.

At baseline, the mean (SD) of CAL for control and experimental group was $6.50(1.38) \mathrm{mm}$ (min 5.12mm; $\max 7.88 \mathrm{~mm}$ ) and 6.14 (1.59) $\mathrm{mm}$ (min 4.55mm; max 7.73mm) (Table 3). Both groups showed significant PPD improvement and CAL gain after 6 weeks $(\mathrm{P}=0.001)$.

Table 2. Plaque Index (PI) and Gingival Index (GI) at baseline and after 6 weeks after scaling and root debridement

\begin{tabular}{lllll}
\hline Variables & $\begin{array}{l}\text { Baseline } \\
\text { Median (IQR) }\end{array}$ & $\begin{array}{l}\text { After 6 weeks } \\
\text { Median (IQR) }\end{array}$ & Z statistic & P value $^{\mathbf{b}}$ \\
\hline Plaque index & $23.20(8.0)$ & $19.05(21.3)$ & -0.239 & 0.668 \\
Gingival index & $22.50(16.3)$ & $19.80(21.7)$ & -1.941 & 0.052 \\
\hline
\end{tabular}

Notes: aWilcoxon Signed Rank Test; bSignificant level is at $\mathrm{P}<0.05$; IQR = Interquartile range.

Table 3. Values of mean (SD) of periodontal pocket depth and clinical attachment level at baseline and after 6 weeks in each group

\begin{tabular}{llll}
\hline Variables & $\begin{array}{l}\text { Evaluation } \\
\text { Point }\end{array}$ & $\begin{array}{l}\text { SRD only (n=194) } \\
\text { Mean (SD) }\end{array}$ & $\begin{array}{l}\text { SRD with honey }(\mathbf{n = 1 7 6}) \\
\text { Mean (SD) }\end{array}$ \\
\hline PPD (mm) & Base line & $5.51(0.53)$ & $5.45(0.46)$ \\
& 6 weeks & $3.81(0.51)$ & $3.84(0.73)$ \\
CAL (mm) & P value $^{\mathrm{a}}$ & 0.001 & 0.001 \\
& Base line & $6.50(1.38)$ & $6.14(1.59)$ \\
& 6 weeks & $4.95(1.30)$ & $4.71(1.28)$ \\
& P value $^{\mathrm{a}}$ & 0.001 & 0.001 \\
\hline
\end{tabular}

Notes: a Independent t-test; PPD = Periodontal pocket depth; CAL = Clinical attachment level; SRD $=$ Scaling and root debridement; $\mathrm{SD}=$ Standard deviation . 
However, no significant difference in the mean (SD) changes in both clinical parameters when compared between groups (Table 4). Both treatment modalities in this study demonstrated statistically significant improvement in the evaluated clinical parameters (PPD and CAL) after 6 weeks of review in the same group compared to baseline. Nevertheless, the difference in mean changes between both groups was not statistically significant.

\section{The effect of local delivery of Tualang honey as an adjunct during SRD versus SRD alone on periodontal biomarker}

A total number of 80 GCF samples were evaluated for the analysis of protein biomarkers. The mean (SD) concentration of GCF MMP-8 at baseline for control group was $0.105(0.038) \mathrm{ng} / \mathrm{ml}$, while the mean (SD) for experimental group was 0.121 (0.058) $\mathrm{ng} / \mathrm{ml}$ (Table 5). After 6 weeks, no reduction of MMP-8 concentration was recorded. As for OPG concentration in GCF, the mean (SD) for the control group was 0.094 (0.005) $\mathrm{ng} / \mathrm{ml}$, which was almost similar to the experimental group mean, 0.095 (0.007) $\mathrm{ng} / \mathrm{ml}$. After 6 weeks, both groups showed a mean OPG concentration of $0.093 \mathrm{ng} / \mathrm{ml}$. Similar to the result for clinical parameters (PPD and CAL), the magnitude of changes from baseline and after 6 weeks showed no significant difference when compared between control and honey groups $(\mathrm{P}=0.62)$ as shown in Table 6.

Table 4. Comparison of the changes of periodontal pocket depth and clinical attachment loss before and after treatment between experimental and control sites

\begin{tabular}{llllll}
\hline Variables & $\begin{array}{l}\text { SRD only } \\
(\mathbf{n = 1 9 4 )} \\
\text { Mean (SD) }\end{array}$ & $\begin{array}{l}\text { SRD with honey } \\
(\mathbf{n = 1 7 6}) \\
\text { Mean (SD) }\end{array}$ & $\begin{array}{l}\text { Mean Differences } \\
(\mathbf{9 5 \%} \mathbf{C I})\end{array}$ & $\begin{array}{l}\mathbf{t} \text { - statistic } \\
(\mathbf{d f})^{\mathrm{a}}\end{array}$ & $\begin{array}{l}\mathbf{P} \\
\text { value }^{\mathbf{b}}\end{array}$ \\
\hline PPD (mm) & $1.69(0.59)$ & $1.62(0.71)$ & $0.08(-0.34,0.50)$ & $0.373(38)$ & 0.503 \\
CAL (mm) & $1.54(0.71)$ & $1.43(0.84)$ & $0.16(-0.34,0.67)$ & $0.66(38)$ & 0.540 \\
\hline
\end{tabular}

Notes: a Independent t-test; bSignificant level is at $\mathrm{P}<0.05$; $\mathrm{PPD}=$ Periodontal pocket depth; $\mathrm{CAL}=$ Clinical attachment level; SRD = Scaling and root debridement; SD = Standard deviation.

Table 5. Values of mean (SD) of inflammatory protein biomarkers at baseline and after 6 weeks in each group

\begin{tabular}{llll}
\hline Variables & Evaluation Point & $\begin{array}{l}\text { SRD only }(\mathbf{n = 2 0}) \\
\text { Mean (SD) }\end{array}$ & $\begin{array}{l}\text { SRD with honey }(\mathbf{n = 2 0}) \\
\text { Mean (SD) }\end{array}$ \\
\hline $\mathrm{MMP}-8$ & Base line & $0.10(0.038)$ & $0.121(0.058)$ \\
$(\mathrm{ng} / \mathrm{ml})$ & 6 weeks & $0.114(0.031)$ & $0.130(0.048)$ \\
& P value $^{\mathrm{a}}$ & 0.21 & 0.54 \\
$\mathrm{OPG}(\mathrm{ng} / \mathrm{ml})$ & Base line & $0.094(0.005)$ & $0.095(0.007)$ \\
& 6 weeks & $0.093(0.004)$ & $0.093(0.003)$ \\
& P value $^{\mathrm{a}}$ & 0.69 & 0.91 \\
\hline
\end{tabular}

Notes: MMP-8 = Matrix metalloproteinase 8; OPG = Osteoprotegerin; SRD = Scaling and root debridement; SD = Standard deviation. 
Table 6. Comparison of the changes of inflammatory protein biomarkers before and after treatment between experimental and control sites $(n=20)$

\begin{tabular}{|llll|l}
\hline Variables & $\begin{array}{l}\text { SRD only (n=20) } \\
\text { Median (IQR) }\end{array}$ & $\begin{array}{l}\text { SRD with honey }(\mathbf{n = 2 0}) \\
\text { Median (IQR) }\end{array}$ & Z statistic $^{\mathrm{a}}$ & $\begin{array}{l}\mathbf{P} \\
\text { valueb }^{\mathbf{b}}\end{array}$ \\
\hline MMP-8 $(\mathrm{ng} / \mathrm{ml})$ & $-0.013(0.07)$ & $-0.002(0.08)$ & -0.598 & 0.550 \\
OPG $(\mathrm{ng} / \mathrm{ml})$ & $0.001(0.01)$ & $-0.001(0.00)$ & -0.392 & 0.696 \\
\hline
\end{tabular}

Notes: aWilcoxon Signed Rank Test; bSignificant level is at $\mathrm{P}<0.05$; MMP-8 $=$ Matrix metalloproteinase 8; OPG = Osteoprotegerin .

\section{Discussion}

This study aimed to evaluate the effect of local delivery of Tualang honey on periodontal tissue healing as an adjunct to SRD in chronic periodontitis by a splitmouth research design. This type of design is commonly used in clinical research related to dentistry where two treatments are randomly assigned to either the right or left halves of the dentition (Lesaffre, 2009). It was introduced by Ramfjord et al. (1968) when they compared the efficacy of two types of periodontal therapy. This design limits the resources needed to conduct a clinical study and also removes a lot of interindividual variability from the estimates of the treatment effect.

The first result demonstrated that scaling and root debridement (SRD), with or without adjunctive of Tualang honey, improve the periodontal clinical findings of patient with chronic periodontitis. SRD is known as a prerequisite for the success of periodontal treatment to halt disease progression and to resolve inflammation. In 2015, the Council on Scientific Affairs (CSA) of the American Dental Association (ADA) made a clinical recommendation that clinicians should consider SRD as the initial treatment of chronic periodontitis (Smiley et al., 2015). SRD is considered as the reference standard and thus used as active control for periodontal trials.

The non-significant findings between the two groups could be due to the single application of honey carried out in the treatment group, in combination with a longtime interval between the baseline and the subsequent measurement, albeit pure concentration honey was used. In contrast to a study by English et al., (2004) which demonstrated that there was a statistically significant reduction of clinical parameters after a 21-days trial period in the test group (Manuka honey), compared to the control group. The differences could be due to the variance in type, frequency, and method of application of honey. In their study, the subjects chewed or sucked Manuka honey products, for 10 minutes, three times a day, after each meal period. Therefore, in the future study, we suggested more frequent application of honey inside the periodontal pockets, for example, a once-daily topical honey application within the first five days of treatment might show the beneficial effect of honey on periodontal tissue healing.

In the second part of study, the presence of MMP-8 and OPG were assessed to determine the progression of chronic periodontitis after the clinical intervention was initiated. Both biomarkers which were collected from gingiva crevicular fluid (GCF) showed nonsignificant finding. MMP-8 is one of the enzymes that belong to the matrix metalloproteinases group. It plays a central role in periodontal ligament remodelling, both in physiological and pathological conditions (Alrowis et al., 2014). OPG is the members of the TNF receptor superfamily besides RANK (receptor activator of nuclear factor $\kappa \mathrm{B}$ ) and RANKL (RANK ligand). OPG is a soluble decoy receptor that has been called the "bone protector" as it protects the skeleton from excessive bone resorption (Simonet et al., 1997). There are several ways on how GCF can be collected such as by intra crevicullar washing, microcapillary, and absorption technique. In this study, we 
choose paper strips technique as it is the most convenient and accurate method for GCF collection (Nazar et al., 2016), followed by the ELISA technique for analysis of biofluids.

Buduneli et al. (2009) evaluated the effects of initial periodontal treatment on GCF levels of IL-17, soluble RANKL, and OPG in smoking and non-smoking patients with chronic periodontitis. The authors reported that GCF OPG levels decreased in smokers and nonsmokers after periodontal therapy that is not observe in this study, this could be due to the differences in the interval for evaluation and number of sites for GCF collection. In this study. GCF only was taken from 2 sites thus leading to a limited amount of GCF that can be collected (between 1-3 $\mu \mathrm{l}$ ). Besides that, there were no intermittent GCF samples were collected between baseline and after 6 weeks review which could be too long to observe an effect. Our result was also in contrast to Shimizu et al. (2016) who showed significant changes of GCF levels of interleukin (IL)-1 $\beta$ and transforming growth factor (TGF)- $\beta$ level after periodontal therapy. Their study was also similar to Buduneli et al., (2009), whereby the GCF samples were collected after 4 weeks interval during the review visit. Other differences could also be due to variation in the expression of different types of cytokines in the GCF (Taso et al., 2019). Additionally, the lack of changes could be due to the washout effect of the honey from the gingival sulcus, thus, limit its local effect on periodontal tissue healing. The GCF flow rate is related to the degree of inflammation and it has been reported that a flow rate of 0.05 to $0.20 \mu \mathrm{l}$ per minute in cases of minimal inflammation. However, the flow rate of GCF can increase up to 30 times at sites of periodontitis as compared to healthy sites (Boström et al., 1999).

A study done by Jaswal and colleagues (2014) utilized a periodontal pack (COE pack) to cover the sites that received clinical intervention in their split-mouth study on evaluation of $2 \%$ turmeric gel in chronic periodontitis patients. They found that the group who received $2 \%$ turmeric gel showed a significant difference in the improvement of PPD and CAL when compared to the control group $(\mathrm{P}<0.001)$. Besides avoiding the risk of spillage, the usage of the COE pack would have minimized the carry-across effect that has been reported as a major problem in a split-mouth design. Therefore, we suggested GCF sample collection could be performed together with the use of COE pack at an earlier time to observe changes in the MMP-8 and OPG level.

\section{Conclusion}

In conclusion, the present study demonstrated significant improvement of PPD and CAL in all periodontal pockets during NSPT. However, within the limitations of the study, the local delivery of Tualang honey as an adjunct, showed no superior effect over SRD alone. Further investigations by controlling any confounding factors such as frequency of Tualang honey application, the sustainability of honey in periodontal pockets, interval between measurements and choosing the appropriate group of chronic periodontitis patients, is recommended.

\section{Acknowledgement}

This study was funded by Universiti Sains Malaysia Short Term Grant (304/ PPSG/ 61312119) and FRGS grant (FRGS/ 203/ PPSG/ 6171220).

\section{References}

Ahmed, S., \& Othman, N. H. (2013). Review of the medicinal effects of tualang honey and a comparison with manuka honey. The Malaysian Journal of Medical Sciences, 20(3), 6-13.

Ainamo, J., Bay, I. (1975). Problems and proposals for recording gingivitis and plaque. International Dental Journal, 25(4), 229-35.

Alrowis, R., Almoharib, H.S., Almubarak, A., Bhaskardoss, J., Preethanath, R., Anil, S. (2014). Oral fluid-based biomarkers in periodontal disease-part 2. Gingival crevicular fluid. Journal of International Oral Health, 6(5), 126-135.

Al-Waili, N.S. (2005). Mixture of honey, beeswax and olive oil inhibits growth of Staphylococcus aureus and Candida albicans. Archives of Medical Research, 36(1), 10-13. 
Armitage, G.C. (1999). Development of a classification system for periodontal diseases and conditions. Annals of Periodontology. 4(1), 1-6.

Atwa, A.D.A., Abushahba, R.Y., Mostafa, M., Hashem, M.I. (2014). Effect of honey in preventing gingivitis and dental caries in patients undergoing orthodontic treatment. Saudi Dental Journal, 26(3), 108-114.

Badet, C., \& Quero, F. (2011). The in vitro effect of manuka honeys on growth and adherence of oral bacteria. Anaerobe, 17(1), 19-22.

Boström, L., Linder, L.E., Bergström, J. (1999). Smoking and crevicular fluid levels of IL-6 and TNF-a in periodontal disease. Journal of Clinical Periodontology, 26(6), 352-357.

Buduneli, N., Buduneli, E., Kütükçüler, N. (2009). Interleukin-17, RANKL, and osteoprotegerin levels in gingival crevicular fluid from smoking and nonsmoking patients with chronic periodontitis during initial periodontal treatment.Journal of Periodontology, 80(8), 1274-1280.

Dentino, A., Lee, S., Mailhot, J., Hefti, A.F. (2013). Principles of Periodontology. Periodontology 2000, 61(1), 16-53.

Eke, P. I., Dye, B. A., Wei, L., Slade, G. D., ThorntonEvans, G. O., Borgnakke, W. S., Taylor, G. W., Page, R. C., Beck, J. D., \& Genco, R. J. (2015). Update on Prevalence of Periodontitis in Adults in the United States: NHANES 2009 to 2012. Journal of Periodontology, 86(5), 611-622.

English, H.K., Pack, A.R., Molan, P.C. (2004). The effects of manuka honey on plaque and gingivitis: a pilot study. Journal of the International Academy of Periodontology, 6(2), 63-7.

Guentsch, A., Kramesberger, M., Sroka, A., Pfister, W., Potempa, J., \& Eick, S. (2011). Comparison of gingival crevicular fluid sampling methods in patients with severe chronic periodontitis. Journal of Periodontology, 82(7), 1051-1060.

Hanes, P.J., Purvis, J.P. (2003). Local anti-infective therapy: pharmacological agents. A systematic review. Annals of Periodontology, 8(1), 79-98.

Hirschfeld, L., Wasserman, B. (1978). A long-term survey of tooth loss in 600 treated periodontal patients. Journal of Periodontology, 49(5), 225-237.

Jaswal, R., Dhawan, S., Grover, V., Malhotra, R. (2014). Comparative evaluation of single application of $2 \%$ whole turmeric gel versus $1 \%$ chlorhexidine gel in chronic periodontitis patients: a pilot study. Journal of Indian Society of Periodontology, 18(5), 575-580.

Khan, F., Abadin, Z.U., Rauf, N. (2007). Honey: nutritional and medicinal value. International Journal of Clinical Practice, 61(10), 1705-1707.

Kishore, R. K., Halim, A. S., Syazana, M. S., Sirajudeen, K. N. (2011). Tualang honey has higher phenolic content and greater radical scavenging activity compared with other honey sources. Nutrition Research, 31(4), 322-325.

Lesaffre, E., Philstrom, B., Needleman I., Worthington H. (2009). The design and analysis of split-mouth studies: what statisticians and clinicians should know. Statistics in Medicine, 28(28), 3470-3482.

Mavric, E., Wittmann, S., Barth, G., \& Henle, T. (2008). Identification and quantification of methylglyoxal as the dominant antibacterial constituent of
Manuka (Leptospermum scoparium) honeys from New Zealand. Molecular Nutrition \& Food Research, 52(4), 483-489.

Nazar Majeed, Z., Philip, K., Alabsi, A., Pushparajan, S., Swaminathan, D. (2016). Identification of gingival crevicular fluid sampling, analytical methods, and oral biomarkers for the diagnosis and monitoring of periodontal diseases: a systematic review. Disease markers, 2016, 1804727.

Olaitan, P.B., Adeleke, O.E., Iyabo, O. (2007). Honey: a reservoir for microorganisms and an inhibitory agent for microbes. African Health Science, 7(3), 159-165.

O'Leary, T.J., Drake, R.B., Naylor, J.E. (1972). The plaque control record. Journal of Periodontolology, 43(1): 38.

Oliver, R.C., Brown, L.J., Löe, H. (1998). Periodontal diseases in the United States population. Journal of Periodontology, 69(2), 269-278.

Oral Health Division Ministry of Health Malaysia. National Oral Health Survey of Adults 2010 (NOHSA)

Ramfjord, S.P., Nissle, R.R., Shick, R.A., Cooper, J.R.H. (1968). Subgingival curettage versus surgical elimination of periodontal pockets. Journal of Periodontology, 39(3), 167-175.

Safii, S. H, Tompkins., G.R., Duncan, W. J. (2017). Periodontal Application of Manuka Honey: Antimicrobial and Demineralising Effects In Vitro. International Journal of Dentistry, 2017:9874535.

Shifrovitch, Y., Binderman, I., Bahar, H., Berdicevsky, I., Zilberman, M. (2009). Metronidazole-loaded bioabsorbable films as local antibacterial treatment of infected periodontal pockets. Journal of Periodontology, 80(2), 330-337.

Shimizu, T., Kubota, T., Iwasaki, M., Morozumi, T., Yoshie, H. (2016). Changes in biomarkers after initial periodontal treatment in gingival crevicular fluid from patients with chronic periodontitis presenting with drug-induced gingival overgrowth. Open Journal of Stomatology 6(2), 6472 .

Simonet, W., Lacey, D., Dunstan, C., Kelley, M., Chang, M.S., Lüthy, R. et al., (1997). Osteoprotegerin: a novel secreted protein involved in the regulation of bone density. Cell, 89(2), 309-319.

Smiley, C.J., Tracy, S.L., Abt, E., Michalowicz, B.S., John, M.T., Gunsolley, J. et al., (2015). Systematic review and meta-analysis on the nonsurgical treatment of chronic periodontitis by means of scaling and root planing with or without adjuncts. Journal of American Dental Association, 146(7), 508-524.

Tan, H. T., Rahman, R. A., Gan, S. H., Halim, A. S., Hassan, S. A., Sulaiman, S. A., \& Kirnpal-Kaur, B. (2009). The antibacterial properties of Malaysian tualang honey against wound and enteric microorganisms in comparison to manuka honey. $B M C$ Complementary and Alternative Medicine, 15(9), 34.

Taso, E., Rakic, M., Stefanovic, V., Petković-Curcin, A., Stanojevic, I., Djukic, M. et al., (2019) Variation of the cytokine profiles in gingival crevicular fluid between different groups of periodontally healthy teeth. Serbian Journal of Experimental and Clinical Research, (published online) 
IIUM Journal of Orofacial and Health Sciences (2021) 2(2): 82-92

Van Ketel, B.A. (1892). Festnummer der berichten van den niederlandsche maatschappij. Bevordering der Pharmacie, 67, 96.

Zainol, M. I., Mohd Yusoff, K., \& Mohd Yusof, M. Y. (2013). Antibacterial activity of selected Malaysian honey. BMC Complementary and Alternative Medicine, 13, 129. 